\title{
2009 GALLERY
}

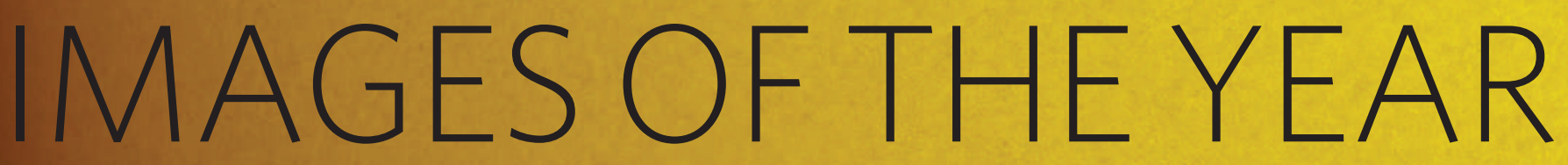

Take a tour through the images that defined 2009, from the murkiest depths of the oceans, where warring worms pepper their enemies with glowing bombs, to the spectacular swirling rainbows thousands of light years away at the heart of the Milky Way.

This year has provided a pictorial panoply, with dust-filled volcanic eruptions captured on film by luck, the tiniest of toads at risk of being lost forever and humankind's outpost in space picked out in detail as it passes in front of the Sun. 

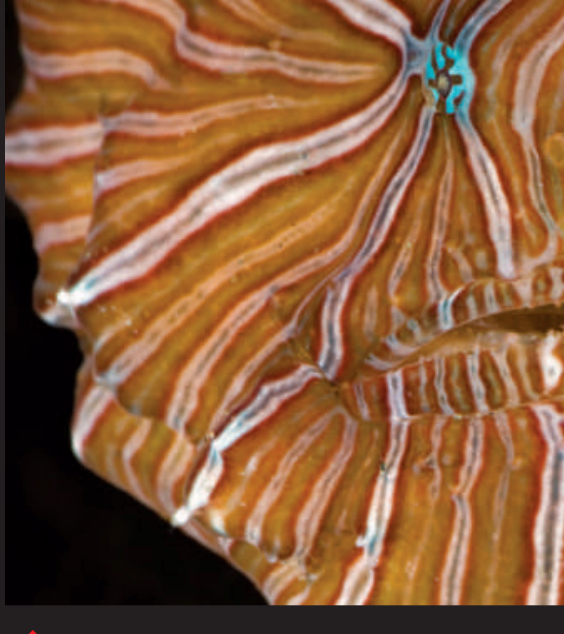

GROOVY

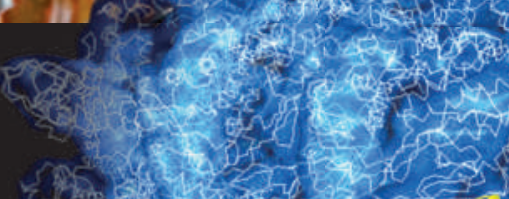

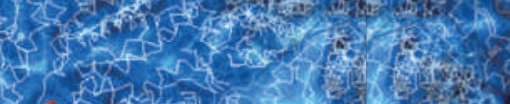

Meet the psychedelic frog fish (Histiophryne psychedelica) Which was discovered by Theodor Pietsch at the University of
Washington, Seattle, and his colleagues, in waters off Indonesi क. and gets around with a lolloping hop along the sea floor.

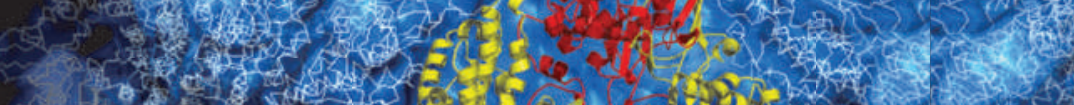

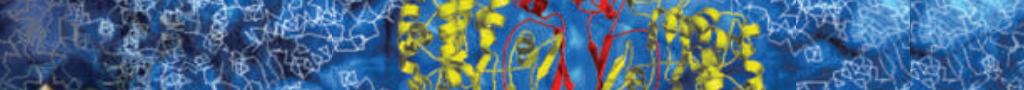

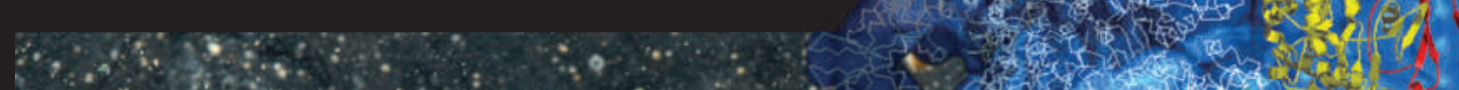
है?
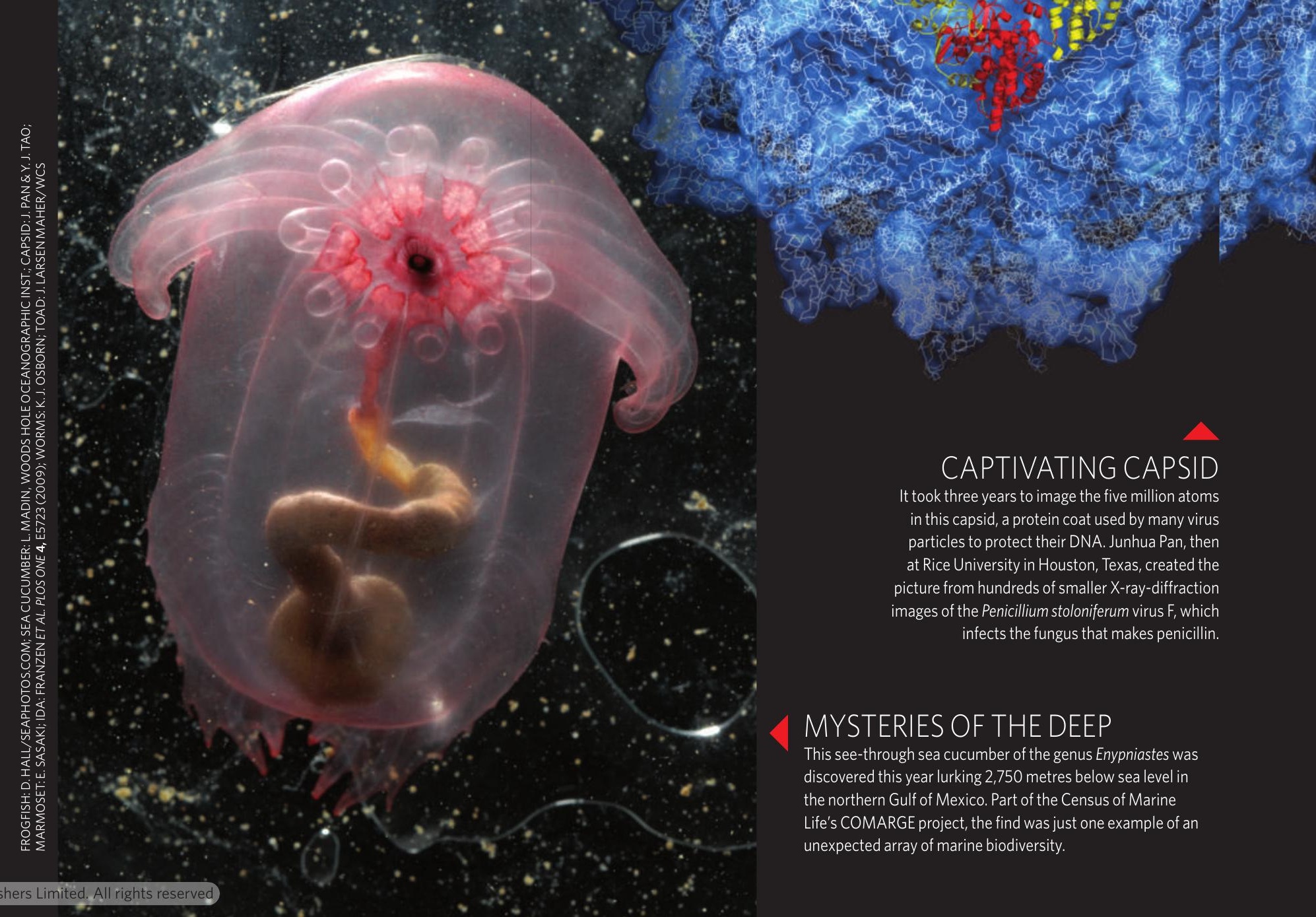
Pat

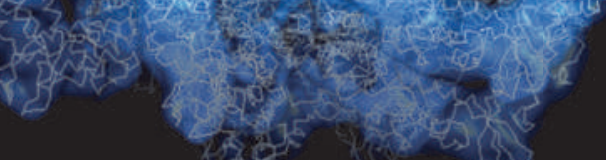

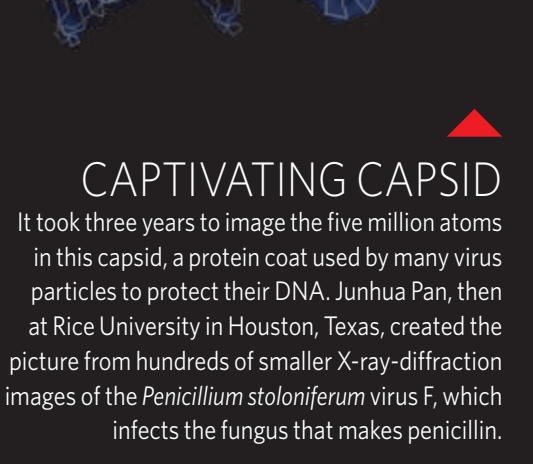




\section{GREEN GENES}

These glowing paws belong to some remarkable marmosets. The animals are the world's first transgenic primates - born to parents with altered genes that express green fluorescent protein. The achievement could help to produce primate models of human diseases.

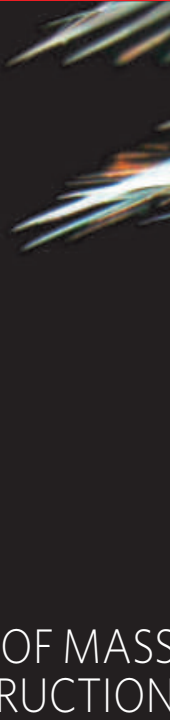

Several species of deep-sea worm with an unusual defensive strategy were discovered by Karen Osborn of the Scripps Institution of Oceanography in La Jolla, California, and her colleagues. The worms scare predators by releasing little bombs that glow green.

\section{WORMS OF MASS DESTRUCTION}
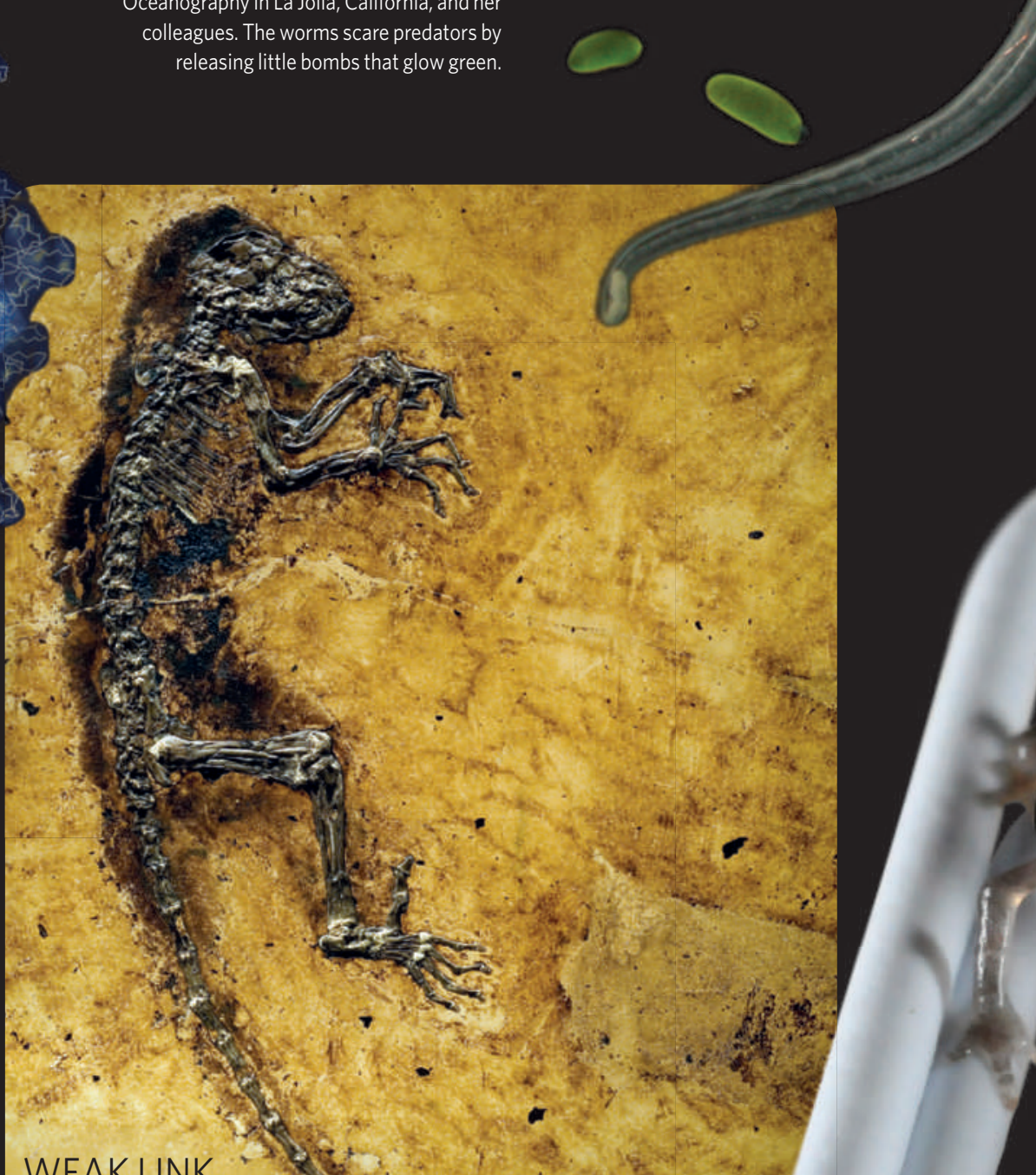

WEAK LINK

In the year that celebrated

200 years since Charles Darwin's

birth, finding a supposed'missing

to human evolution raised a media storm.

The hype around Ida (Darwinius masillae), a

47-million-year-old primate-like fossil, soon

turned sour - she is much closer to lemurs

than humans on the tree of life.
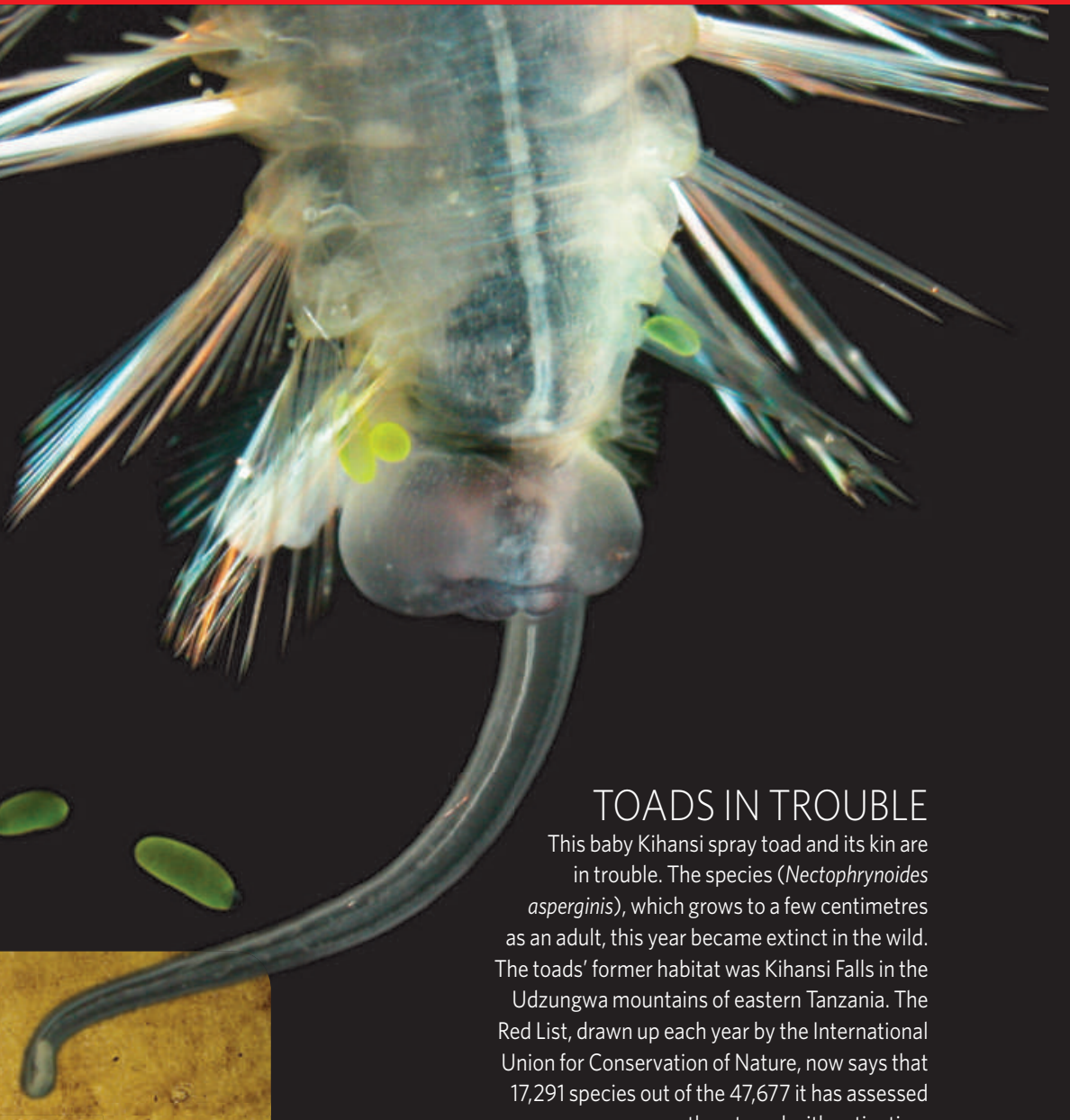

TOADS IN TROUBLE

This baby Kihansi spray toad and its kin are

in trouble. The species (Nectophrynoides

asperginis), which grows to a few centimetres as an adult, this year became extinct in the wild. The toads' former habitat was Kihansi Falls in the Udzungwa mountains of eastern Tanzania. The Red List, drawn up each year by the International Union for Conservation of Nature, now says that 17,291 species out of the 47,677 it has assessed are threatened with extinction.

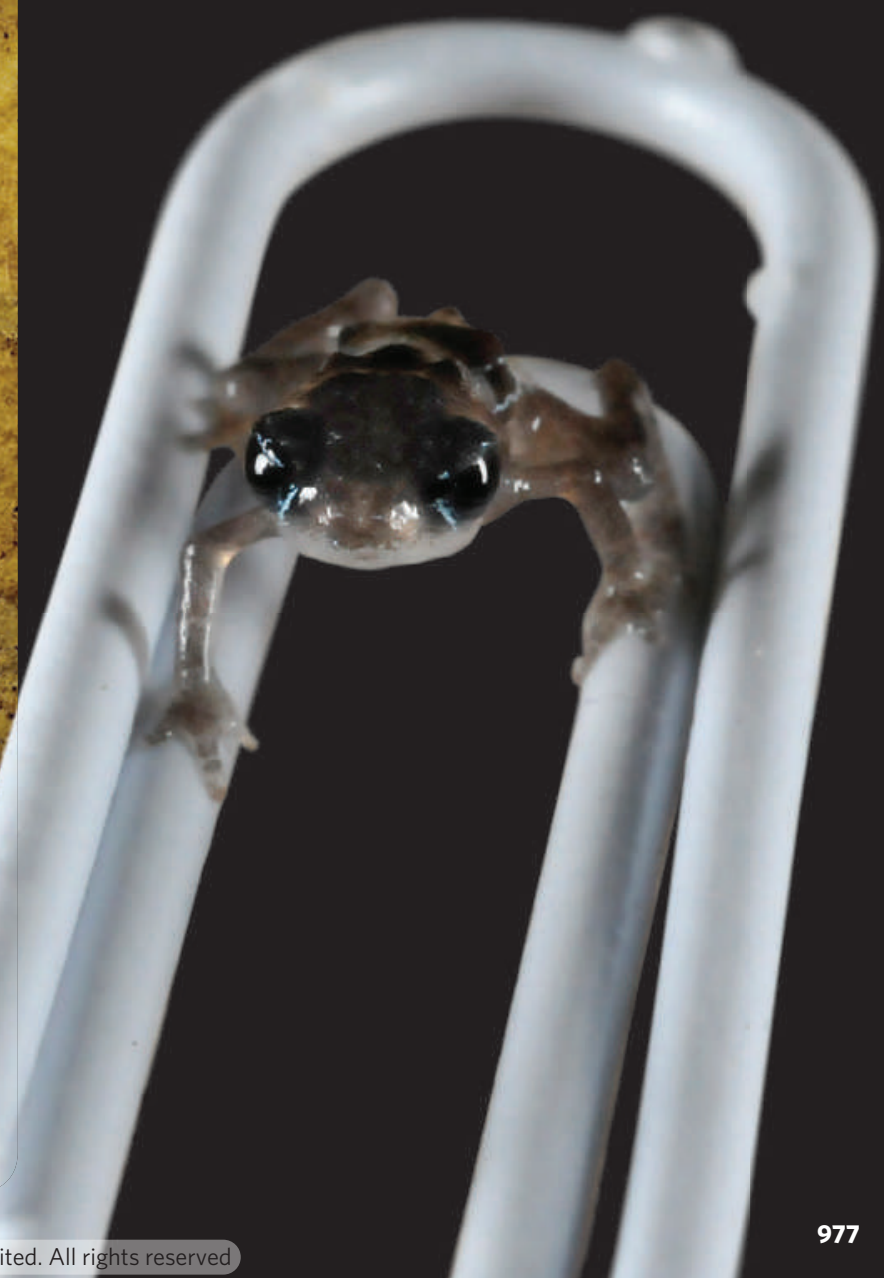

